\title{
SYNTHESIS AND CHARACTERIZATION OF HYBRID ORGANIC-INORGANIC THIN FILMS VIA ATOMIC LAYER DEPOSITION FOR MEMS/NEMS
}

\author{
D. Seghete ${ }^{I}$, Y. J. Chang ${ }^{2}$, B. Davidson', V.M. Bright ${ }^{2}$, and S.M. George ${ }^{l}$
}

${ }^{1}$ Department of Chemistry and Biochemistry, University of Colorado at Boulder

${ }^{2}$ Department of Mechanical Engineering, University of Colorado at Boulder

\section{ABSTRACT}

We report a hybrid atomic layer deposition (ALD) / molecular layer deposition (MLD) approach that produces a new class of hybrid organic-inorganic films. These novel films have very low densities, yet display typical ALD characteristics: controllable linear growth, conformality, low roughness, and uniform composition. The etch behavior of these materials indicates that they are completely removed in acidic solutions. Due to their low density and high carbon content, the new hybrid materials are promising as protective coatings and sacrificial layers in MEMS/NEMS devices.

\section{INTRODUCTION}

Atomic layer deposition (ALD) is a thin film deposition technique that produces accurately controlled, dense inorganic films at low processing temperatures. $\mathrm{Al}_{2} \mathrm{O}_{3}$ ALD has been used previously as micro-/ nano-scale structural material [1-3] (Fig. 1) and protective and wear resistant coating in MEMS devices [4, 5].

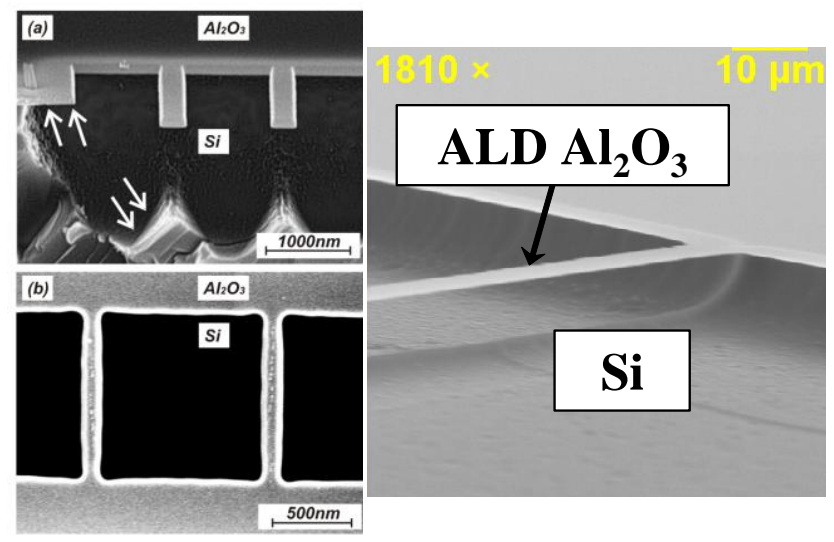

Figure 1. $\mathrm{ALD} \mathrm{Al} l_{2} \mathrm{O}_{3}$ structures grown at either $177^{\circ} \mathrm{C}$ or $120^{\circ} \mathrm{C}$.

(A)

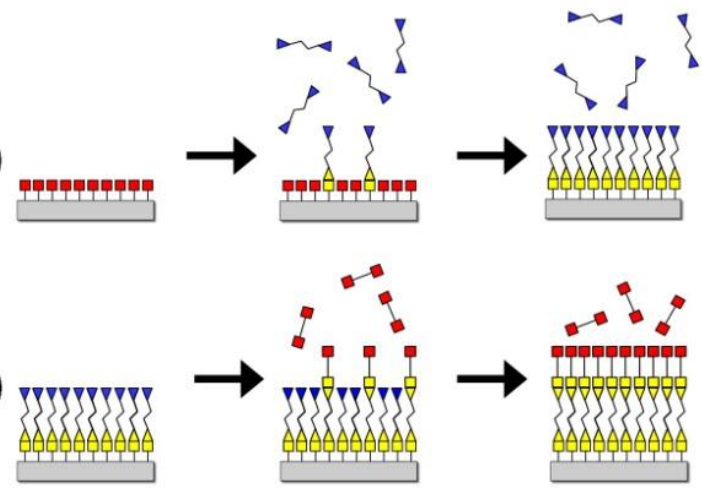

Figure 2. Schematic of the most general binary ALD or MLD system. For ALD the precursors are small inorganic molecules, while in MLD they are larger bifunctional organic species.
Molecular layer deposition (MLD) is a sequential selflimiting surface chemistry process similar to atomic layer deposition (ALD) [6]. As shown in Fig. 2, during MLD growth two bifunctional organic precursors are used to produce a purely organic film [7, 8]. The ability to perform ALD for inorganic materials and MLD for organic materials suggests an extension to a hybrid MLD/ALD approach using organic and inorganic precursors for hybrid organic-inorganic film growth.

Two general classes of hybrid ALD/MLD materials are reported. First is a binary system, where two precursors are used: an inorganic reactant, trimethylaluminum (TMA) and an organic reactant, ethylene glycol (EG). This hybrid system produces polymeric aluminum alkoxides, or alucones [9]. The second class of hybrid systems uses three reactants: an inorganic molecule, TMA, a heterobifunctional organic molecule, ethanolamine (EA), and a cyclic molecule, maleic anhydride (MA) [10]. This new approach requires three steps, and the obtained hybrid organic / inorganic films is referred to as " $\mathrm{ABC}$ ". The extension to threestep ABC MLD processes expands the variety of reactants and compositional diversity that can be achieved with MLD. a)
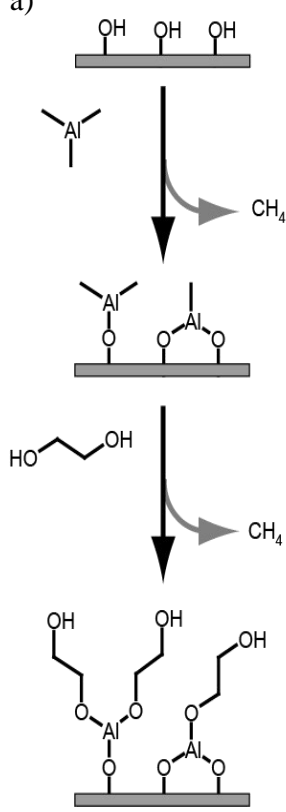

b)

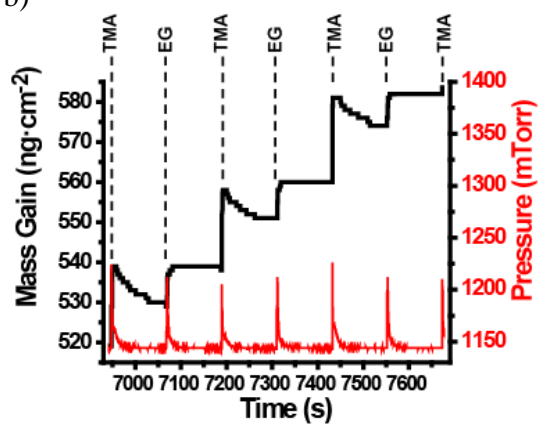

c)

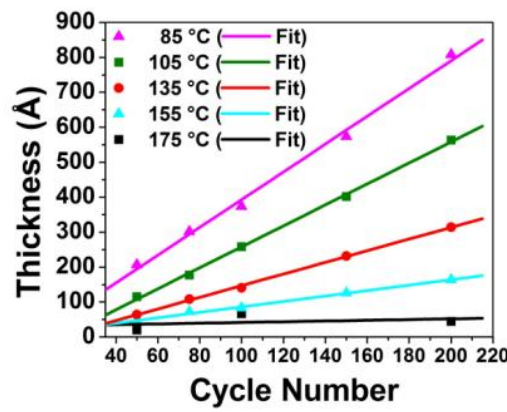

Figure 3. Surface chemistry and growth characteristics for the $A B$ alucone: (a) schematic of the reaction mechanism, (b) quartz crystal microbalance mass gains during TMA and EG exposures, and $(c)$ linear growth vs. number of cycles for various growth temperatures, as measured by $x$-ray reflectivity 


\section{RESULTS AND DISCUSSION}

\section{Alucone Growth}

As illustrated in Figure 3a, the alucone growth is a binary self-limiting process [9]. The initial exposure of the surface to trimethylaluminum leads to a reaction with the -OH hydroxyl species on the surface. At the end of this reaction, when all the hydroxyls are consumed, the surface functionality is changed entirely from hydroxyl to $-\mathrm{AlCH}_{3}$ methyl species. After a purge of the extra reactants and biproducts, the surface is exposed to ethylene glycol. One hydroxyl end of this molecule reacts with the $-\mathrm{AlCH}_{3}$ methyl species, producing and aluminum alkoxide on the surface. The other end of the molecule regenerates the hydroxyl terminated surface. After all the $-\mathrm{AlCH}_{3}$ methyl species have reacted, a purge step removes the extra reactants and products. Since the newly formed surface has the same hydroxyl functionality as the initial surface, the process can be repeated in a cyclic fashion.

Figure $3 \mathrm{~b}$ displays the mass gains during TMA and EG exposures for steady state growth recorded by the in situ quartz crystal microbalance (QCM) at $135{ }^{\circ} \mathrm{C}$ [9]. Details about our experimental setup have been given elsewhere [11]. The decrease in mass gain during TMA exposure occurred over a period of 6090s. This long progressive decrease is much longer than the time required for the TMA to return back to the baseline pressure in other ALD systems. Mass gains with decreases of this type have been observed previously during $\mathrm{Al}_{2} \mathrm{O}_{3}$ ALD on polymers [12].

Ex situ $\mathrm{x}$-ray reflectivity (XRR) scans confirmed the linear growth of alucone films versus number of cycles over a wide range of temperatures [9]. As shown in Figure 3c, the alucone growth rates were inversely proportional to the growth temperature. Growth rates varied between $4 \AA$ per cycle at $85^{\circ} \mathrm{C}$ and $1.7 \AA$ per cycle at $135^{\circ} \mathrm{C}$. The growth rates measured with XRR agreed very well with in situ results from the QCM. Although the growth rates varied inversely proportional to temperature, the density of the films remained relatively constant at $1.5 \mathrm{~g} / \mathrm{cm}^{3}$ [9].

\section{ABC Growth}

The surface chemistries involved in the growth of the new ABC films is schematically shown in Figure 4a [10]. Similar to alucone, TMA is the inorganic species used in the first step to react with the hydroxylated surface and produce $-\mathrm{AlCH}_{3}$ methyl species. In the second step, ethanolamine, a hetero-bifunctional molecule is used to change the functionality from methyl to amine. In the third step, maleic anhydride is dosed to react with the amine groups in a ring-opening reaction to produce carboxyl groups on the surface. The resulting carboxyls are identical in functionality to the hydroxyls in the first step and allow the three step process to be repeated in a cyclic fashion. The resulting polymeric film is composed of monomer units that contain one $\mathrm{Al}$ atom, six $\mathrm{C}$ atoms, four $\mathrm{O}$ atoms and one $\mathrm{N}$ atom.

In situ QCM studies showed that the $\mathrm{ABC}$ hybrid material grows linearly versus number of cycles, as indicated in Figure $4 \mathrm{~b}$ [10]. Similar to the alucone mass gain profile, the slow decrease in mass after the TMA dose suggests the low density, and hence polymeric character of the grown $\mathrm{ABC}$ film. As measured ex situ by XRR, the average growth rate for the $\mathrm{ABC}$ film was $23 \AA$ /cycle at $90^{\circ} \mathrm{C}$ and $11 \AA /$ cycle at $110^{\circ} \mathrm{C}$ (Figure 4c) [10].

\section{Physical Properties}

XRR scans revealed that the $\mathrm{ABC}$ films had very low roughness and very uniform composition. As shown in Figure 5, Bragg peaks are sharp even past 8000 arcseconds. Such high reflectivity at large angles in an XRR experiment suggests minimum scattering at the interfaces. This behavior is obtained for

very smooth films that have a roughness correlated with the underlying layer. For the film in Figure 5, the $560 \AA$ thick film had a roughness of $5 \AA$, which is similar to the typical roughness of the Si substrates used in the experiment. The good agreement between the experimental scan and the theoretical fit confirms the uniform composition of the obtained $\mathrm{ABC}$ film.

a)

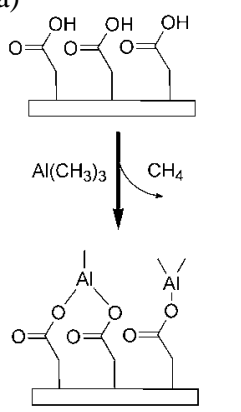

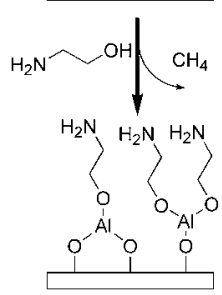
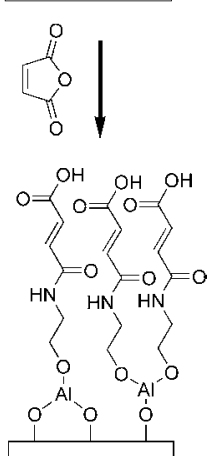

Figure 4. Surface chemistry and growth characteristics for the ABC films: (a) reaction mechanism, (b) QCM mass profile for four cycles, and (c) linear growth vs. number of cycles for different growth temperatures, as measured by XRR

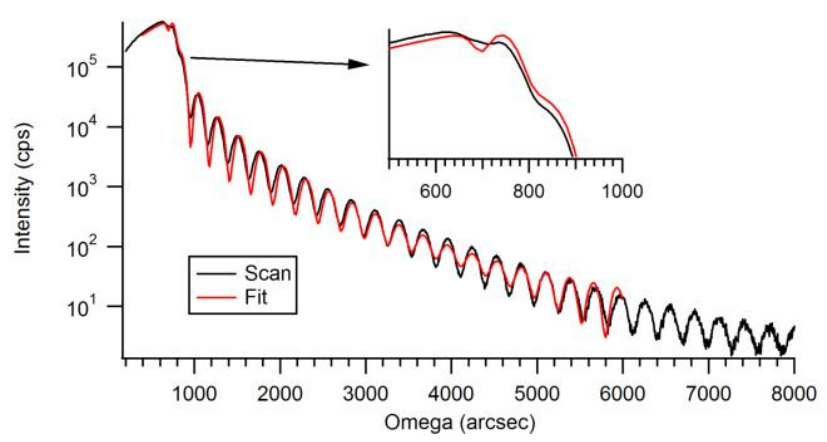

Figure 5. XRR scan of a typical $A B C$ film grown at $90^{\circ} \mathrm{C}$. The critical angle (inset) provides the density of the material, $1.6 \mathrm{~g} / \mathrm{cm}^{3}$, while the periodicity of the Bragg peaks confirms the low roughness and uniformity of the $A B C$ films. 
Nanoindentation of alucone films measured an average Young's modulus of $18.8 \mathrm{GPa}$ and an average Berkovitch hardness of $1.46 \mathrm{GPa}$. These values are higher than those of typical polymers $(\sim 10 \mathrm{GPa}$ and $\sim 0.5 \mathrm{GPa})$ but lower than values typical for metals or ceramics $(\sim 100 \mathrm{GPa}$ and $\sim 10 \mathrm{GPa})$.

\section{Etch Behavior}

Both dry-etching and wet-etching behaviors of the $\mathrm{ABC}$ film were investigated. Reactive ion etch (RIE) with oxygen was performed on the $\mathrm{ABC}$ films. The smooth initial $\mathrm{ABC}$ film was transformed into two layers. The bottom layer had the same density as the initial ABC film, while the top layer was denser. The plasma process leads to the formation of a passivation layer that prevent further etching as shown in Table 1.

Table 1. Film structure before and after reactive ion etching with oxygen, as measured by XRR

\begin{tabular}{|c|c|c|c|}
\hline Material & $\begin{array}{c}\text { Thickness } \\
(\AA \mathbf{\AA})\end{array}$ & $\begin{array}{c}\text { Density } \\
\mathbf{3} \\
(\mathbf{g} / \mathbf{c m})\end{array}$ & $\begin{array}{c}\text { Roughness } \\
(\mathbf{\AA})\end{array}$ \\
\hline \multicolumn{4}{|c|}{ Initial } \\
\hline $\mathrm{ABC}$ & 591.5 & 1.59 & 6.2 \\
\hline \multicolumn{4}{|c|}{ After $\mathbf{O}_{\mathbf{2}}$ plasma } \\
\hline ABC & 223.0 & 1.59 & 50.0 \\
\hline Unknown & 289.7 & 2.08 & 6.6 \\
\hline
\end{tabular}

As for wet-etching behavior, the $\mathrm{ABC}$ film was immersed into different solutions. As shown in Table 2, aprotic solvents did not interact with the $\mathrm{ABC}$ material. This result confirmed that the $\mathrm{ABC}$ film contains covalently bonded organic molecules. If the organic precursors were simply condensed on the surface, or if the amide linkage would not have been achieved, the aprotic solvents were expected to solvate the hydrophobic organic backbone of the molecule. Consequently, some of the $\mathrm{ABC}$ film would have been etched.

Table 2. Wet etch behavior of the ABC films in various solutions

\begin{tabular}{|c|c|c|c|}
\hline Solvent & $\begin{array}{c}\text { Solvent } \\
\text { type }\end{array}$ & $\begin{array}{c}\text { Observations } \\
\text { after 90 min }\end{array}$ & $\begin{array}{c}\text { Film structure by } \\
\text { XRR after 90 min }\end{array}$ \\
\hline Toluene & $\begin{array}{c}\text { non- } \\
\text { polar }\end{array}$ & $\begin{array}{c}\text { no visible } \\
\text { change }\end{array}$ & no change \\
\hline Acetone & $\begin{array}{c}\text { polar } \\
\text { aprotic }\end{array}$ & $\begin{array}{c}\text { no visible } \\
\text { change }\end{array}$ & no change \\
\hline Isopropanol & $\begin{array}{c}\text { polar } \\
\text { protic }\end{array}$ & $\begin{array}{c}\text { color change } \\
\text { formation of } \\
\text { spots }\end{array}$ & $\begin{array}{c}\text { thickness decrease } \\
\text { film roughening } \\
\text { two films formed }\end{array}$ \\
\hline $1 \mathrm{M} \mathrm{NaOH}$ & basic & $\begin{array}{c}\text { folar } \\
\text { protic } \\
\text { formation of } \\
\text { spoted white } \\
\text { film }\end{array}$ & $\begin{array}{c}\text { thickness decrease } \\
\text { film roughening } \\
\text { two films formed }\end{array}$ \\
\hline $1 \mathrm{M} \mathrm{HCl}$ & acidic & $\begin{array}{c}\text { complete } \\
\text { removal of } \\
\text { polymer film }\end{array}$ & bare Si substrate \\
\hline
\end{tabular}

Both protic solvents had similar effects on the ABC film. The resulting two layer structure with the formation of a denser layer at the top is similar to the result obtained after the dry etch process. The interaction with the proton-containing solutions is in agreement with the observation that the alucone MLD films were susceptible to degradation upon exposure to water. The exact mechanism of this proton-mediated process is not yet understood.
While the $1 \mathrm{M}$ basic solution led to the formation of a white precipitate on the sample, the $1 \mathrm{M}$ acidic solution was successful in etching the $\mathrm{ABC}$ film. This contrasting behavior can be explained by the chemical composition of the $\mathrm{ABC}$ film. The existing amide linkage could react with the base solution to form carboxylic acid salts that are insoluble. In contrast, the ammonium chloride salt formed in the reaction with the acid solution is soluble, leading to a complete etch of the $\mathrm{ABC}$ film. The acid etching is promising for using the $\mathrm{ABC}$ layer as a sacrificial material in MEMS/NEMS structures.

\section{Potential Applications}

Multilayers that combine alternate soft/flexible layers with hard/brittle layers have extraordinary mechanical properties. These multilayer structures are exploited in one of the strongest structures in nature, the nacreous layer of the mollusk shell $[13,14]$. The unique organic-inorganic structure of nacre produces approximately two times the mechanical strength and approximately one thousand times the fracture toughness of its inorganic material [15]. Given the contrast between Young's modulus values of the alucone and $\mathrm{ABC}$ films and other typical ALD systems (e.g. alumina, tungsten), alternating multilayer structures could be fabricated to imitate the nacreous shell structure (Figure 6). Such high toughness structures could be used to coat conformally MEMS devices and improve their wear resistance.

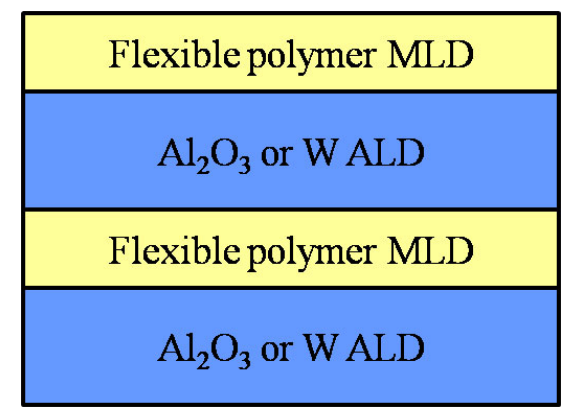

Figure 6. High toughness hard/soft multilayer to be used as wear resistant coating for MEMS/NEMS devices.

Ultra-thin film micro-/nano-scale resonators are another promising application of the novel hybrid materials. Nanoresonators have been used for precise mass detection [16] or high frequency applications [17]. The availability of ALD materials with contrasting mechanical properties allows for the design of composite materials with desired mechanical properties for MEMS/NEMS devices. The composite mechanical properties of a multilayer structure could be tuned by varying the ratio of organic to inorganic material. This control over the mechanical properties could be used to create a resonator with a tunable resonant frequency.

Alucone and $\mathrm{ABC}$ films can also be used as sacrificial spacer layers for MEMS/NEMS structures. Very thin hybrid organic/inorganic film can be grown at low temperatures with high conformity and low roughness. Embedding these films as sacrificial layers in the manufacturing process can produce MEMS devices with Ångstrom-level precision vertical gaps after release.

A layer of $80 \mathrm{~nm}$ thick MLD alucone was first deposited on silicon substrates at $80^{\circ} \mathrm{C} .2 \mathrm{~nm} \mathrm{Al}_{2} \mathrm{O}_{3}$ and $20 \mathrm{~nm} \mathrm{~W}$ were deposited on top of the alucone layer at $120^{\circ} \mathrm{C}$. After patterning AZP photoresist on the ALD W layer, tungsten etchant and $0.05 \%$ HF were used to etch the ALD W and ALD alumina, respectively. The patterned AZP photoresist was then removed by acetone. 
Diluted $\mathrm{NaOH}$ was used to remove the MLD alucone under W ALD structure. The sample was then immersed in methanol and dried in a $\mathrm{CO}_{2}$ critical point dryer. The released structure is shown in Figure 7. The upright W ALD structure is due to the mechanical stress within the W ALD thin film. This residual stress can be further tuned by varying the growth temperature and film thickness of the W ALD layer.

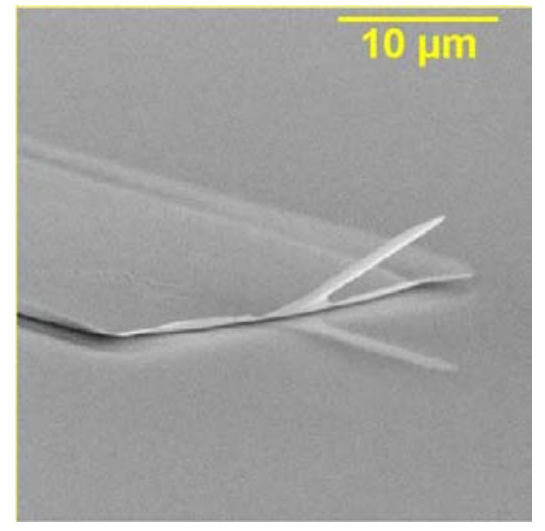

Figure 7. ALD $W$ cantilever released via wet-etch from $80 \mathrm{~nm}$ ALD/MLD alucone layer.

\section{CONCLUSIONS}

We demonstrated the growth of novel hybrid organicinorganic films using ALD/MLD techniques. In situ characterization showed the self-limiting and linear growth behaviors typical for ALD systems. The physical properties of these materials suggest a polymeric character. Due to their high carbon content and since they etch in acidic solutions, these new materials are suitable as sacrificial layers in MEMS devices. In addition, the reported films could be used as protective layers for MEMS applications when embedded in periodic organic/inorganic structures with exceptional mechanical properties.

\section{ACKNOWLEDGEMENTS}

This research was supported by DARPA NEMS (SPAWAR Contract No.: N66001-07-1-2033), DARPA Award \# HR0011-061-0048, the DARPA Focus Center for Integrated Micro/NanoMechanical Transducers (iMINT Center) at the University of Colorado, Boulder and the Air Force Office of Scientific Research.

\section{REFERENCES}

[1] Y. J. Chang, K. Cobry, and V. M. Bright, "Atomic Layer Deposited Alumina for Micromachined Resonators," 21st IEEE International Conference on Micro Electro Mechanical Systems (MEMS 2008), Tucson, USA, Jan. 13-17, 2008, pp. 387-390.

[2] M. K. Tripp, C. F. Herrmann, S. M. George, and V. M. Bright, "Ultra-thin multilayer nanomembranes for short wavelength deformable optics," 17th IEEE International Conference on Micro Electro Mechanical Systems. Maastricht MEMS 2004 Technical Digest. pp. 77-80.

[3] M. K. Tripp, C. Stampfer, D. C. Miller, T. Helbling, C. F. Hermann, C. Hierold, K. Gall, S. M. George, and V. M. Bright, "The mechanical properties of atomic layer deposited alumina for use in micro- and nano-electromechanical systems," Sensors and Actuators A - Physical, vol. 130, pp. 419-429, Aug, 2006.
[4] N. D. Hoivik, J. W. Elam, R. J. Linderman, V. M. Bright, S. M. George, and Y. C. Lee, "Atomic layer deposited protective coatings for micro-electromechanical systems," Sensors and Actuators A - Physical, vol. A103, no. 1-2, pp. 100-8, 2003.

[5] T. M. Mayer, J. W. Elam, S. M. George, P. G. Kotula, and R. S. Goeke, "Atomic-layer deposition of wear-resistant coatings for microelectromechanical devices," Applied Physics Letters, vol. 82, no. 17, pp. 2883-2885, 2003.

[6] S. M. George, A. W. Ott, and J. W. Klaus, "Surface chemistry for atomic layer growth," Journal of Physical Chemistry, vol. 100, no. 31, pp. 13121-13131, Aug, 1996.

[7] Y. Du, and S. M. George, "Molecular layer deposition of nylon 66 films examined using in situ FTIR spectroscopy," Journal of Physical Chemistry C, vol. 111, no. 24, pp. 85098517, Jun, 2007.

[8] N. M. Adamczyk, A. A. Dameron, and S. M. George, "Molecular Layer Deposition of Poly(p-phylene trephthalamide) Films Using Trephtaloyl Chloride and pPhenylenediamine," in press, Langmuir, 2008.

[9] A. A. Dameron, D. Seghete, B. B. Burton, S. D. Davidson, A. S. Cavanagh, J. A. Bertrand, and S. M. George, "Molecular Layer Deposition of Alucone Polymer Films Using Trimethylaluminum and Ethylene Glycol," Chemistry of Materials, in press, 2008.

[10] B. Yoon, D. Seghete, and S. M. George, to be published, 2008.

[11] J. W. Elam, M. D. Groner, and S. M. George, "Viscous flow reactor with quartz crystal microbalance for thin film growth by atomic layer deposition," Review of Scientific Instruments, vol. 73, no. 8, pp. 2981-2987, Aug, 2002.

[12] C. A. Wilson, R. K. Grubbs, and S. M. George, "Nucleation and growth during $\mathrm{Al}_{2} \mathrm{O}_{3}$ atomic layer deposition on polymers," Chemistry of Materials, vol. 17, no. 23, pp. 56255634, Nov, 2005.

[13] F. Barthelat, H. Tang, P. D. Zavattieri, C. M. Li, and H. D. Espinosa, "On the mechanics of mother-of-pearl: A key feature in the material hierarchical structure," Journal of the Mechanics and Physics of Solids, vol. 55, no. 2, pp. 306-337, Feb, 2007.

[14] G. Mayer, "Rigid biological systems as models for synthetic composites," Science, vol. 310, no. 5751, pp. 1144-1147, Nov, 2005.

[15] B. Yeom, S. Kim, J. H. Cho, J. Hahn, and K. Char, "Effect of interfacial adhesion on the mechanical properties of organic/inorganic hybrid nanolaminates," Journal of Adhesion, vol. 82, no. 5, pp. 447-468, May, 2006.

[16] Z. J. Davis, G. Abadal, O. Kuhn, O. Hansen, F. Grey, and A. Boisen, "Fabrication and characterization of nanoresonating devices for mass detection," Journal of Vacuum Science \& Technology B, vol. 18, no. 2, pp. 612-616, Mar-Apr, 2000.

[17] M. Li, H. X. Tang, and M. L. Roukes, "Ultra-sensitive NEMS-based cantilevers for sensing, scanned probe and very high-frequency applications," Nature Nanotechnology, vol. 2, no. 2, pp. 114-120, Feb, 2007. 